Canadian

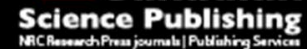

Canadian Journal of Chemistry Revue canadienne de chimie

\title{
Bonding Properties of FCC-like Au44(SR)28 Clusters from X- ray Absorption Spectroscopy
}

\begin{tabular}{|c|c|}
\hline Journal: & Canadian Journal of Chemistry \\
\hline Manuscript ID & cjc-2017-0169.R1 \\
\hline Manuscript Type: & Article \\
\hline Date Submitted by the Author: & 23-Jun-2017 \\
\hline Complete List of Authors: & $\begin{array}{l}\text { Yang, Rui; Dalhousie University, Chemistry } \\
\text { Chevrier, Daniel; Dalhousie University, Chemistry } \\
\text { Zeng, Chenjie; Carnegie Mellon University } \\
\text { Jin, Rongchao; Carnegie Mellon University, Chemistry } \\
\text { Zhang, Peng; Dalhousie University, Chemistry }\end{array}$ \\
\hline $\begin{array}{r}\text { Is the invited manuscript for } \\
\text { consideration in a Special } \\
\text { Issue?: }\end{array}$ & TK Sham \\
\hline Keyword: & $\begin{array}{l}\text { face-centered cubic (FCC)-like, X-ray absorption spectroscopy (XAS), } \\
\text { thiolate-protected gold clusters, bonding properties }\end{array}$ \\
\hline
\end{tabular}


Page 1 of 18

\title{
Bonding Properties of FCC-like $\mathrm{Au}_{44}(\mathrm{SR})_{28}$ Clusters from X-ray Absorption Spectroscopy
}

\author{
Rui Yang ${ }^{1}$, Daniel M. Chevrier ${ }^{1}$, Chenjie Zeng ${ }^{2}$, Rongchao Jin $^{2}$, Peng Zhang ${ }^{1 *}$ \\ ${ }^{1}$ Department of Chemistry, Dalhousie University, Halifax, Nova Scotia, B3H 4R2, Canada \\ ${ }^{2}$ Department of Chemistry, Carnegie Mellon University, Pittsburgh, Pennsylvania 15213, United \\ States
}


Page 2 of 18

Abstract: Thiolate-protected gold clusters with precisely controlled atomic composition have recently emerged as promising candidates for a variety of applications because of their unique optical, electronic and catalytic properties. The recent discovery of the $\operatorname{Au}_{44}(S R)_{28}$ total structure is considered as an interesting finding in terms of the face-centered cubic (FCC)-like core structure in small gold-thiolate clusters. Herein, the unique bonding properties of $\mathrm{Au}_{44}(\mathrm{SR})_{28}$ is analyzed using temperature-dependent $\mathrm{X}$-ray absorption spectroscopy (XAS) measurements at the $\mathrm{Au} \mathrm{L}_{3}$-edge, and compared with other FCC-like clusters such as $\mathrm{Au}_{36}(\mathrm{SR})_{24}$ and $\mathrm{Au}_{28}(\mathrm{SR})_{20}$. A negative thermal expansion was detected for the $\mathrm{Au}-\mathrm{Au}$ bonds of the metal core (the first Au-Au shell), and was interpreted based on the unique $\mathrm{Au}$ core structure consisting of the $\mathrm{Au}_{4}$ units. EXAFS fitting results from $\mathrm{Au}_{28}(\mathrm{SR})_{20}$, $\mathrm{Au}_{36}(\mathrm{SR})_{24}$ and $\mathrm{Au}_{44}(\mathrm{SR})_{28}$ show a size dependent negative thermal expansion behavior in the first $\mathrm{Au}-\mathrm{Au}$ shell, further highlighting the importance of the $\mathrm{Au}_{4}$ units in determining the $\mathrm{Au}$ core bonding properties, and shedding lights on the growth mechanism of these FCC-like Au clusters.

Keywords: thiolate-protected gold clusters, face-centered cubic (FCC)-like, X-ray absorption spectroscopy (XAS), negative thermal expansion

\section{Introduction}

Thiolate-stabilized Au clusters are one of the most widely studied Au clusters due to their high stability and functional surface environment. ${ }^{1-4}$ The development of precisely 
size-controlled synthesis of these Au clusters allows for a variety of size-specific studies ${ }^{5-15}$ such as the bonding and electronic properties ${ }^{3,16-20}$. Recent studies on the thiolate stabilized Au clusters indicated their varied core structures such as the icosahedral Au core ${ }^{7,12,21}$ the face-centered-cubic (FCC)-like Au core ${ }^{8-11}$ and others ${ }^{6,14}$. Among these clusters, FCC-like Au clusters attract significant amount of interest because these ultrasmall particles exhibit unexpected core structure of FCC geometry, similar to that of bulk gold. ${ }^{16,17,22-24}$ The reported $\mathrm{Au}_{44}(\mathrm{SR})_{28}$ is one of the thiolate protected Au clusters with a FCC-like core structure in the FCC-like series including the well-studied $A u_{28}(S R)_{20}$ and $A u_{36}(S R)_{24}{ }^{8,10,11}$ In the research of Au clusters, XAS has been found useful to probe the bonding properties of these $\mathrm{Au}$ clusters. ${ }^{3}$ For instance, the unique structural and electronic properties were found in $\mathrm{Au}_{28}(\mathrm{SR})_{20}$ and $\mathrm{Au}_{36}(\mathrm{SR})_{24}$ clusters by comparing with icosahedral Au clusters, where the small tetrahedral $\mathrm{Au}_{4}$ units within the gold cores play a very important role in controlling their bonding and electronic properties. ${ }^{16,17}$ Furthermore, based on the results from temperature-dependent X-ray absorption spectroscopy (XAS) experiments, it is interesting to note that a negative thermal expansion was found in the first $\mathrm{Au}-\mathrm{Au}$ shell in $\mathrm{Au}_{36}(\mathrm{SR})_{24}$, but not in $\mathrm{Au}_{28}(\mathrm{SR})_{20}$ clusters. ${ }^{16,17}$ However, such studies only focus on individual sizes of $\mathrm{Au}$ clusters by comparing the FCC with the icosahedral counterpart. The overall trend of size-dependent bonding in FCC-like "magic series" from the XAS perspective is still unavailable with only two Au clusters $\left(\mathrm{Au}_{28}(\mathrm{SR})_{20}\right.$ and $\left.\mathrm{Au}_{36}(\mathrm{SR})_{24}\right)$.

In this work, we have compared the recently discovered $\mathrm{Au}_{44}(\mathrm{SR})_{28}$ with the other two $\mathrm{Au}$ clusters $\left(\mathrm{Au}_{28}(\mathrm{SR})_{20}\right.$ and $\left.\mathrm{Au}_{36}(\mathrm{SR})_{24}\right)$. Based on a multi-shell EXAFS fitting analysis and temperature-dependent XAS measurements, the size-dependent bonding behavior of these 
Page 4 of 18

clusters is discussed herein. This work, together with our previous studies, highlights the bonding trend in the FCC-like magic series.

\section{Experimental Methods}

$\mathrm{Au}_{28}(\mathrm{SR})_{20} \mathrm{NCs}$ were prepared from the reaction between excess thiol ligands and $\mathrm{Au}_{25}(\mathrm{SR})_{18}$-precursor at $80{ }^{\circ} \mathrm{C}$ for 2 hours. ${ }^{10}$ Using a similar method, the $\mathrm{Au}_{36}(\mathrm{SR})_{24} \mathrm{NCs}$ were prepared from the reaction between excess thiol ligands and $\mathrm{Au}_{38}(\mathrm{SR})_{24}$ precursor at $80{ }^{\circ} \mathrm{C}$ for more than 12 hours. ${ }^{11}$ Unlike the above FCC-like Au NCs, the $A u_{44}(S R)_{28} N C s$ were synthesized using both routes via a two-step "size focusing" process. In the first step, size-mixed $\mathrm{Au}_{x}(\mathrm{SR})_{y} \mathrm{NCs}$ were formed from $\mathrm{HAuCl}_{4}$ precursor (i.e. atoms to clusters). In the second step, the size-mixed NCs were dissolved in toluene and etchant thiol ligands. After reacting at $60{ }^{\circ} \mathrm{C}$ for 24 hours, $\mathrm{Au}_{44}(\mathrm{SR})_{28} \mathrm{NCS}$ were produced in high field. ${ }^{8}$ All the syntheses produced Au NCs in high purity which is supported by Mass Spec data. The Au $\mathrm{L}_{3}$-edge XAS measurements were then carried out in transmission mode at the Sector20-BM beamline of the Advanced Photon Source (Argonne National Laboratory, IL, U.S.A.). $\mathrm{Au}_{44}(\mathrm{SR})_{28}$ powder samples were packed into Kapton film pouches, sealed and folded to ensure high quality EXAFS signals are collected. The samples were measured in transmission mode which is represented using $\log \left(I_{0} / I_{1}\right) \cdot{ }^{25}$ Here, $I_{0}$ is the intensity of the incident beam and $I_{1}$ is intensity of the transmitted beam. A Au foil reference was placed in between the $I_{1}$ detector and another detector $I_{2}$ to simultaneously collect the XAFS data for calibration of the energy of $\mathrm{Au} \mathrm{L}_{3}$ absorption edge. 


$$
\chi(k)=\sum_{j} \frac{S_{0}^{2} N_{j} e^{-2 k^{2} \sigma_{j}^{2}} e^{-2 R_{j} / e^{\lambda(k)}} f_{j}(k)}{k R_{j}^{2}} \sin \left[2 k R_{j}+\delta_{j}(k)\right]
$$

The data measured from Au foil can then be used to determine the amplitude reduction factor $\left(S_{0}{ }^{2}=0.9\right)$ as shown in the EXAFS equation, where $N$ is the coordination number, $\sigma^{2}$ is the Debye-Waller factor, $\lambda(k)$ is the photoelectron mean-free path and $R$ is the scattering distance. Scattering amplitude functions $(f(k))$ and phase-shift functions $(\lambda(k))$ in the EXAFS equation can be used to simulate specific scattering route by theoretical calculations. Here, the XAS data were collected at both low temperature (LT: 90K) using a helium-cooled cryostat chamber and room temperature (RT: 300K) under ambient conditions.

The XAS data processing and fitting were performed using the WinXAS 3.1 software package $^{25}$ and FEFF8.2 computer code ${ }^{26}$. In the refinement process, the amplitude reduction factor $\left(S_{0}{ }^{2}\right)$ of 0.9 was obtained by fitting the Au foil EXAFS and fixed for the EXAFS fitting of Au clusters. For multishell EXAFS fitting, coordination numbers (CN) of Au-S and Au-Au shells are fixed based on the published $\mathrm{Au}_{44}(\mathrm{SR})_{28}$ total structure. ${ }^{8} \mathrm{~A}$ k-range of $3-14 \AA^{-1}$ was used for fitting the EXAFS of $\mathrm{Au}_{44}(\mathrm{SR})_{28}$ and a shorter k-range $\left(3-11.25 \AA^{-1}\right)$ was used for qualitatively comparing the EXAFS of the three clusters in order to make their k-range consistent for the comparison. All the $E_{0}$ shift values were correlated to reduce the number of free running parameters, allowing for the incorporation of up to three scattering shells.

\section{Results and discussion}

\subsection{Qualitative XAS comparison}


Page 6 of 18

The Au L $\mathrm{L}_{3}$-edge XANES of $\mathrm{Au}_{28}(\mathrm{SR})_{20}, \mathrm{Au}_{36}(\mathrm{SR})_{24}$ and $\mathrm{Au}_{44}(\mathrm{SR})_{28}$ is first compared in Figure 1. Interestingly, when the XANES is closely compared in the overlapped plot in Figure, identical features are observed for the three clusters in the whole XANES region, including the white line (the first feature following the absorption edge) intensity. These observations imply that their electronic properties are identical and independent of the cluster size. A more detailed discussion on this finding will be presented together with the EXAFS fitting results in the later section.

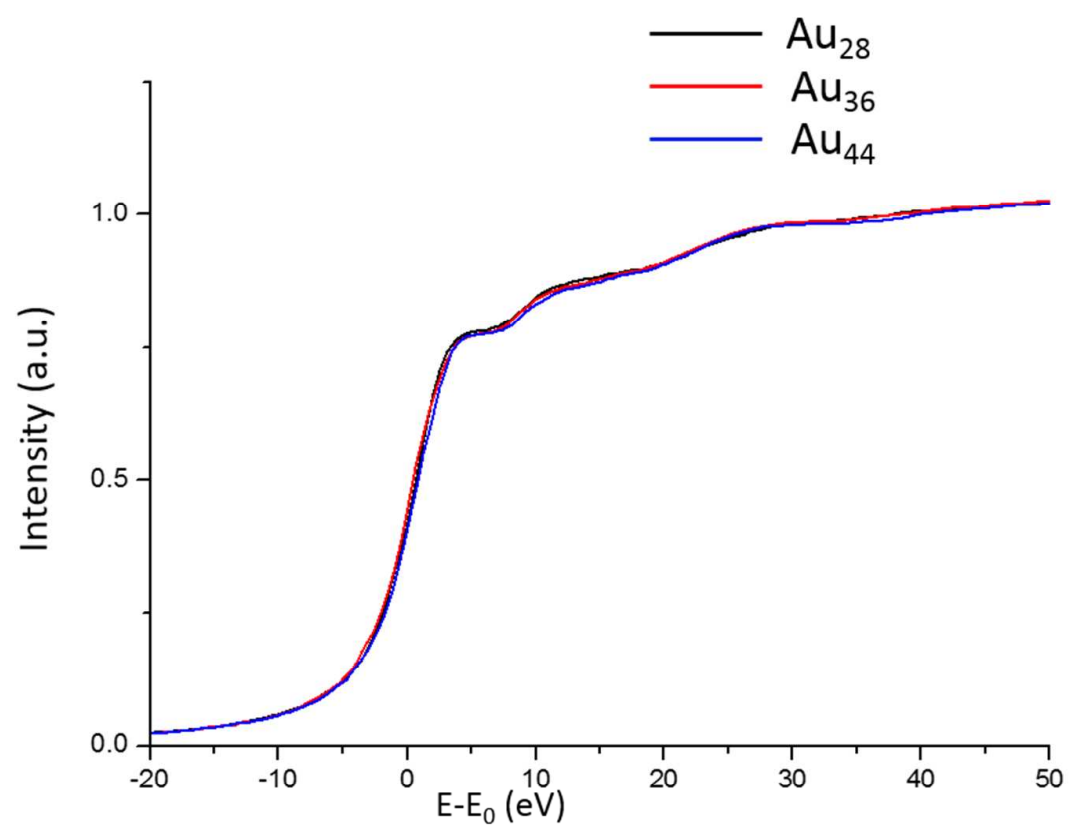

Figure 1. Overlapped XANES of $\mathrm{Au}_{28}(\mathrm{SR})_{20}, \mathrm{Au}_{36}(\mathrm{SR})_{24}$ and $\mathrm{Au}_{44}(\mathrm{SR})_{28}$.

The FT-EXAFS of $\mathrm{Au}_{28}(\mathrm{SR})_{20}, \mathrm{Au}_{36}(\mathrm{SR})_{24}$ and $\mathrm{Au}_{44}(\mathrm{SR})_{28}$, collected at room and low temperatures (RT and LT), are next plotted in Figure 2. The most intense peak around $1.9 \AA$ in each spectrum is caused by the Au-S scattering. The intensity of these peaks decreases when their size increases in both RT and LT series. To understand this trend, we calculated the CN 
Page 7 of 18

of the Au-S coordination when the cluster size increases. The Au-S CN gives a value of 1.43 for $\mathrm{Au}_{28}(\mathrm{SR})_{20}, 1.33$ for $\mathrm{Au}_{36}(\mathrm{SR})_{24}$ and 1.27 for $\mathrm{Au}_{44}(\mathrm{SR})_{28}$. From these calculated $\mathrm{CN}$ values, we can understand that the observed trend for these EXAFS peaks is caused by the decrease
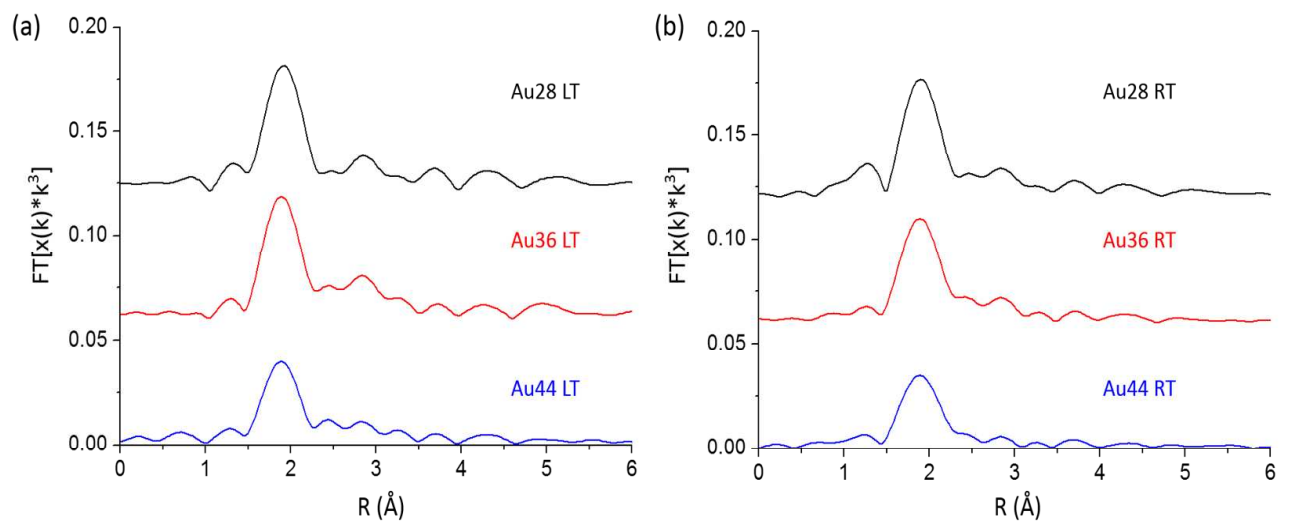

Figure 2. FT-EXAFS of $\mathrm{Au}_{28}(\mathrm{SR})_{20}, \mathrm{Au}_{36}(\mathrm{SR})_{24}$ and $\mathrm{Au}_{44}(\mathrm{SR})_{28}$ at $\mathrm{RT}$ and LT. In the comparison, the k-range of 3-11.25 $\AA^{-1}$ was used for all the Au clusters.

of Au-S CNs when the cluster size increases. Furthermore, the small peaks between $2.5 \AA$ and 3.5 ̊ correspond to Au-Au scattering. The similar patterns of the FT-EXAFS of the three Au clusters at RT and LT indicate a similar local structure for these FCC-like Au clusters. In addition, spectra with lower peak intensity in the Au-Au scattering region are found at RT comparing with the LT data. This is because thermal vibrations at higher temperature lead to a higher degree of thermal disorder, which reduces the EXAFS scattering intensity.

Quantitative information of these scattering shells will be obtained by the refinement of FT-EXAFS in the next section.

\subsection{EXAFS fitting analysis of $\mathrm{Au}_{44}(\mathrm{SR})_{28}$}


In order to perform a reliable EXAFS analysis, the bond distance distribution of $\mathrm{Au}_{44}(\mathrm{SR})_{28}$ was first studied based on the reported total structure. ${ }^{8}$ Three scattering shells were found,

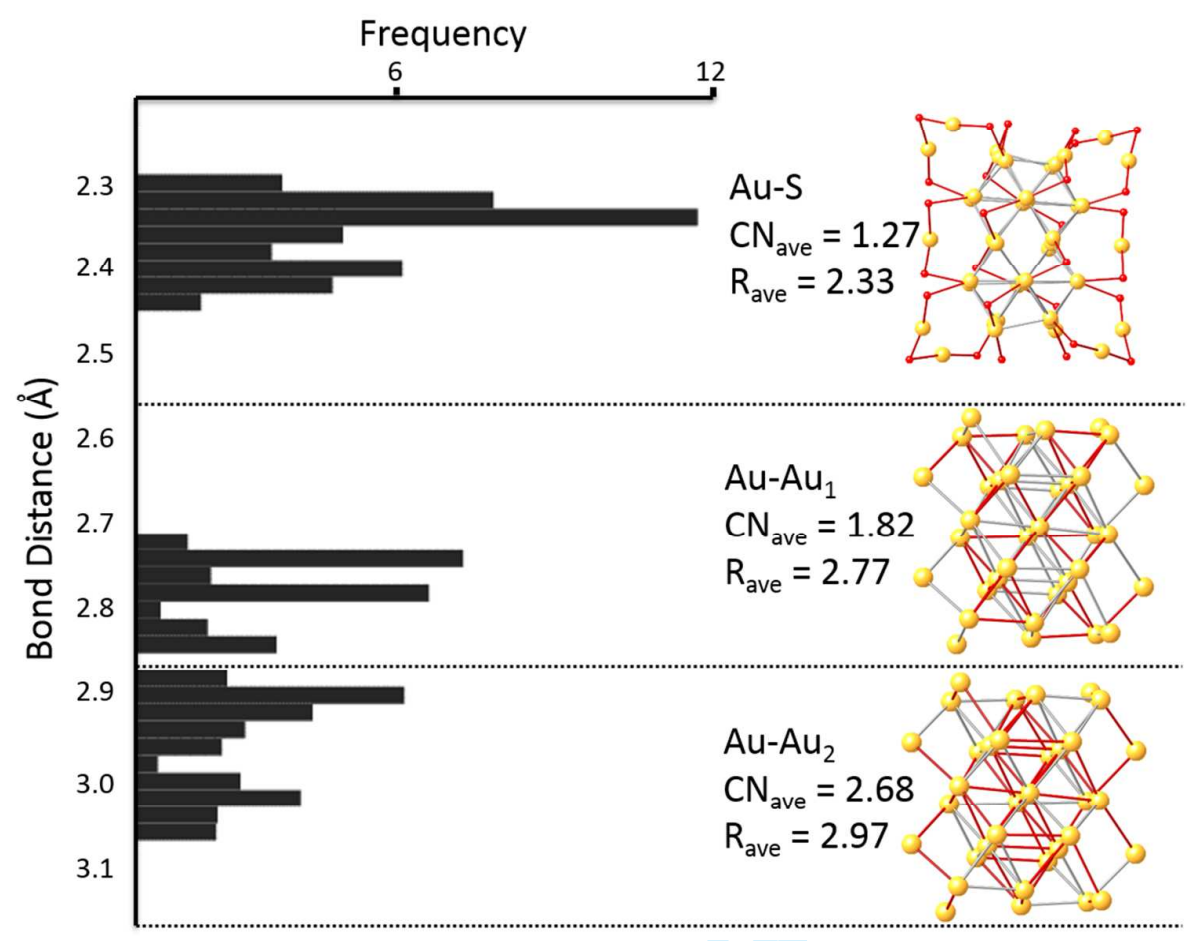

Figure 3. Bond distance distribution for $\mathrm{Au}_{44}(\mathrm{SR})_{28}$ and representative EXAFS scattering shells.

The bonds in each shell are represented by red sticks.

which are displayed in Figure 3. The first shell with the shortest distance corresponds to the $\mathrm{Au}-\mathrm{S}$ bonds in the clusters. The other two longer distance shells are caused by the Au-Au interactions. The shorter $\mathrm{Au}-\mathrm{Au}$ shell $\left(\mathrm{Au}-\mathrm{Au} \mathrm{u}_{1}\right)$ in the region of 2.707-2.849 $\AA$ accounts for the $\mathrm{Au}-\mathrm{Au}$ bonding within the $\mathrm{Au}_{4}$ unit of the cluster core. The longer $\mathrm{Au}-\mathrm{Au}$ shell $\left(\mathrm{Au}-\mathrm{Au}_{2}\right)$ in the region of 2.877-3.104 ̊̊ corresponds to the long distance Au-Au interactions between surface, bridge and center Au atoms.

The theoretical $\mathrm{CN}$ was calculated from the bond distance distribution (Figure 3). For the Au-S scattering shell, the average $\mathrm{CN}$ is found to be 1.27 ((56 Au-S bonds)/44 Au atoms). The 
Page 9 of 18

average $\mathrm{CN}$ for $\mathrm{Au}-\mathrm{Au}_{1}$ and $\mathrm{Au}-\mathrm{Au}_{2}$ scattering shells are 1.82 ((40 Au-Au bonds) *2 / $44 \mathrm{Au}$ atoms) and 2.68 ((59 Au-Au bonds) *2 / 44 Au atoms), respectively. The calculated CNs of the Au-S and two Au-Au scattering shells can then be used in the EXAFS fit, and were fixed in the EXAFS refinement process.
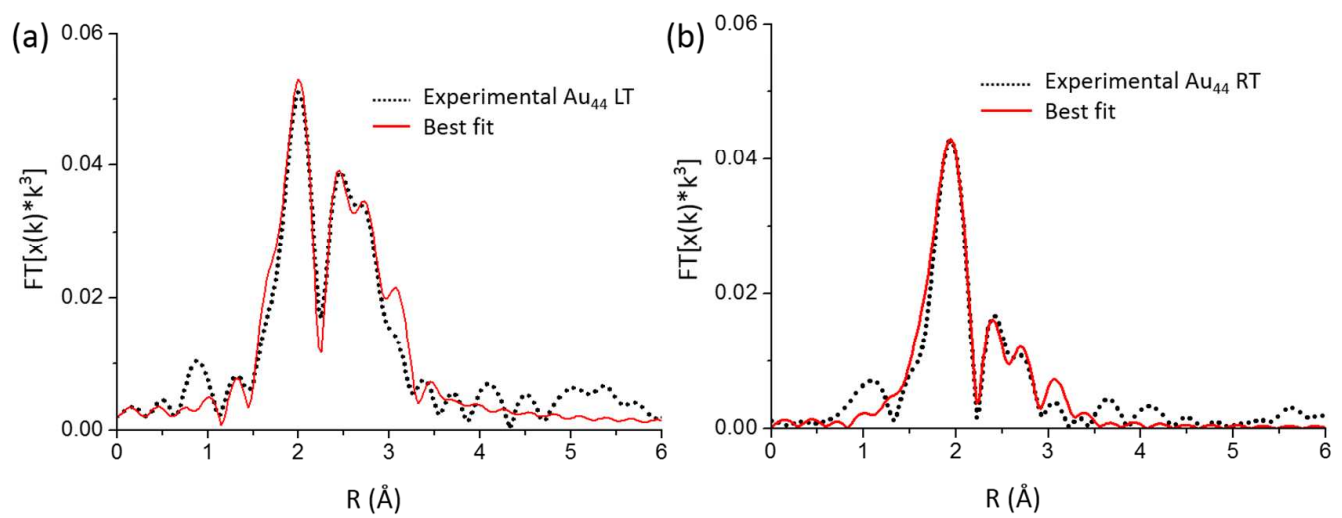

Figure 4. Experimental FT-EXAFS (k-range: $3-14 \AA^{-1}$ ) and the best fits for $A_{4}(S R)_{28}$ at (a) RT and (b) LT.

To verify the reliability of the assignment of these three shells, a three shell Au $\mathrm{L}_{3}$-edge EXAFS $\left(\mathrm{Au}-\mathrm{S}, \mathrm{Au}-\mathrm{Au}_{1}, \mathrm{Au}-\mathrm{Au}_{2}\right)$ fit was performed for $\mathrm{Au}_{44}(\mathrm{SR})_{28}$ at $\mathrm{LT}$ since the total structure was also previously obtained at $\mathrm{LT}^{8}{ }^{8}$ Figure 4 a) shows the best fit of $\mathrm{Au}_{44}(\mathrm{SR})_{28}$ at $90 \mathrm{~K}$ and the fitting results are recorded in Table 1. From Table 1, it can be seen that the bond distances of Au-S (2.33 $\AA$ ), Au-Au $u_{1}\left(2.74 \AA\right.$ ) and $A u-A u_{2}(2.93 \AA$ ) shells determined from the EXAFS refinement are very consistent with the calculated bond lengths from the total structure (i.e. Au-S: $\left.2.33 \AA, A u-A u_{1}: 2.77 \AA, A u-A u_{2}: 2.97 \AA\right)$. This verifies the reliability of the three shell fitting method used in this work. 
Table 1. EXAFS multi-shell fitting results of $\mathrm{Au}_{44}(\mathrm{SR})_{28}$ at both $\mathrm{LT}$ and $\mathrm{RT}$.

\begin{tabular}{|c|c|c|c|c|c|}
\hline Temperature(K) & Shells & $\mathrm{CN}^{\mathrm{a}}$ & $R(\AA ̊)$ & $\sigma^{2}\left(\AA^{2}\right)$ & $\Delta \mathrm{E}_{0}(\mathrm{eV})$ \\
\hline \multirow[t]{3}{*}{90 (LT) } & Au-S & 1.27 & $2.327(9)$ & $0.0048(6)$ & $1.60(2)$ \\
\hline & $A u-A u_{1}$ & 1.82 & $2.744(9)$ & $0.0038(4)$ & $1.60(0)$ \\
\hline & $\mathrm{Au}-\mathrm{Au}_{2}$ & 2.68 & $2.930(12)$ & $0.008(1)$ & $1.60(0)$ \\
\hline \multirow[t]{3}{*}{300 (RT) } & Au-S & 1.27 & $2.321(10)$ & $0.0061(6)$ & $-0.10(17)$ \\
\hline & $\mathrm{Au}-\mathrm{Au}_{1}$ & 1.82 & 2.724 (17) & $0.0080(9)$ & $-0.10(0)$ \\
\hline & $\mathrm{Au}-\mathrm{Au}_{2}$ & 2.68 & $2.907(24)$ & $0.012(3)$ & $-0.10(0)$ \\
\hline${ }^{\mathrm{a}} \mathrm{CN}$ values & ed tc & 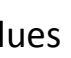 & ed from & structur & errors for \\
\hline \multicolumn{6}{|c|}{ fixed CN values). Difference in the uncertainty values is associated with both the data } \\
\hline
\end{tabular}

Next, we performed fits on the RT EXAFS to study the temperature dependent properties of $\mathrm{Au}_{44}(\mathrm{SR})_{28}$. The Au-S bond distance is essentially unchanged when the temperature is varied. However, the distances of both the $A u-A u_{1}$ and $A u-A u_{2}$ shells are found to be sensitive to the change in temperature. When the temperature increases from $90 \mathrm{~K}$ to $300 \mathrm{~K}$, the bond distances of the $\mathrm{Au}-\mathrm{Au}_{1}$ shell display a negative thermal expansion (NTE) behavior, that is, a decrease from $2.744 \AA$ to $2.724 \AA$ (decrement $=0.020 \AA$ ). The $A u-A u_{2}$ shell also shows a NTE from $2.930 \AA$ to $2.907 \AA$ (decrement $=0.023 \AA$ ). It has been known that the tetrahedral $\mathrm{Au}_{4}$ units within the gold core of other FCC-like clusters such as $\mathrm{Au}_{28}(\mathrm{SR})_{20}$ and $\mathrm{Au}_{36}(\mathrm{SR})_{24}$ play an 
important role in controlling their electronic properties. ${ }^{16,17}$ Therefore, we next focus on a close comparison of the temperature-dependent behavior of the $\mathrm{Au}-\mathrm{Au}_{1}$ shells for these three FCC-like clusters.

\subsection{The size-dependent trend}

In previous studies, the $\mathrm{Au}-\mathrm{Au}$ shell in $\mathrm{Au}_{28}(\mathrm{SR})_{20}$ appears to be invariant to the temperature change, remaining at around $2.73(2) \AA$ at both $\mathrm{LT}$ and $\mathrm{RT} .{ }^{17}$ Unlike $\mathrm{Au}_{28}(\mathrm{SR})_{20}$, the $\mathrm{Au}-\mathrm{Au}_{1}$ shell in $\mathrm{Au}_{36}(\mathrm{SR})_{24}$ displays a NTE, that is, the Au-Au distance decreases from

\subsection{5}

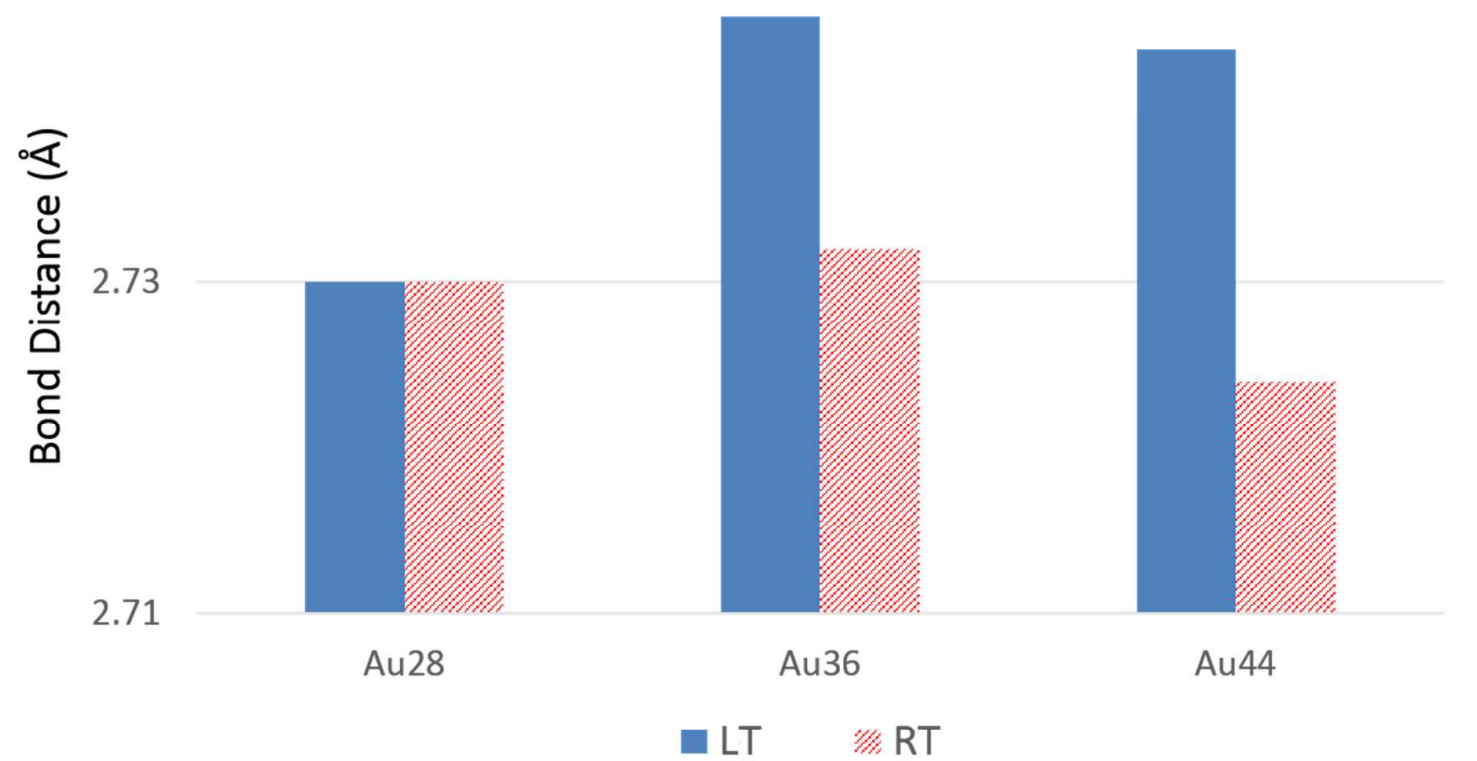

Figure 5. Bond distances of $A u-A u_{1}$ in $A_{2}(S R)_{20}, A_{36}(S R)_{24}$ and $A u_{44}(S R)_{28}$ clusters at $\mathrm{LT}$ (blue) and RT (red).

$2.746(3) \AA$ to $2.732(4) \AA$ as the temperature increases. ${ }^{16}$ Comparing with $\mathrm{Au}_{36}(\mathrm{SR})_{24}$, $\mathrm{Au}_{44}(\mathrm{SR})_{28}$ shows an even more pronounced NTE in the $\mathrm{Au}-\mathrm{Au}_{1}$ shell. These results are summarized in Figure 5. Therefore, the change of bond distances in the $\mathrm{Au}-\mathrm{Au}_{1}$ shells shows 
an interesting size-dependent trend for the three Au clusters, that is, the NTE becomes stronger when the size of the Au clusters increases.

(a)

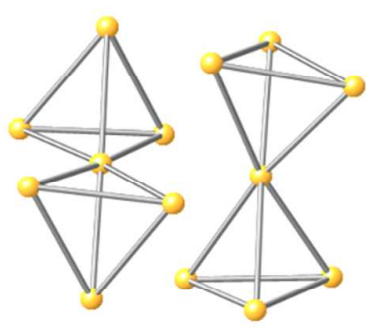

(b)

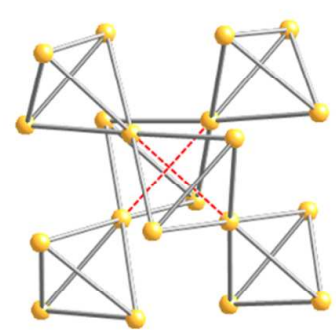

(c)

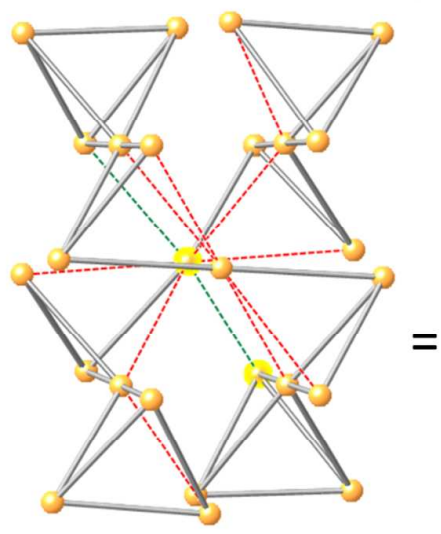

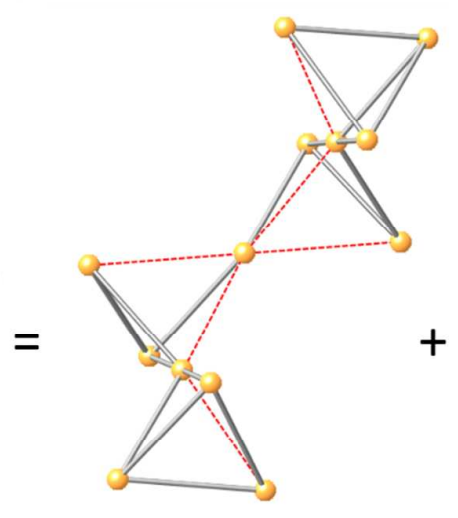

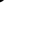

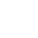


$\mathrm{Au}_{4}$ units which are connected by sharing three corner $\mathrm{Au}$ atoms. To more clearly see these $\mathrm{Au}_{4}$ units within $\mathrm{Au}_{44}(\mathrm{SR})_{28}$, the two sets of $\mathrm{Au}_{4}$ units are plotted separately in Figure $6 \mathrm{c}$ ). Note that for all these structures, the Au-Au bonds are identified based on a specific bond distance ( $2.880 \AA$ from bulk $\mathrm{Au}$ ) which is the commonly used metallic Au-Au bond distance. When the Au-Au distances within the tetrahedral unit are longer than $2.880 \AA$, these $A u-A u$ bonds are considered as non-metallic bonds (i.e. metallic bonds missing), and are shown with red dashed lines (Figure 6). In $\mathrm{Au}_{28}(\mathrm{SR})_{20}$, all the metallic bonds are well maintained in the $\mathrm{Au}_{4}$ units. As the size of the Au clusters increases, the $A u_{4}$ tetrahedrons begin to lose $\mathrm{Au}-\mathrm{Au}$ metallic bonds. Specifically, two metallic bonds are missing in $\mathrm{Au}_{36}(\mathrm{SR})_{24}$ and ten are missing in $\mathrm{Au}_{44}(\mathrm{SR})_{28}$. (Figure 6. a-c)

The missing metallic bonds shown in the Figure 6, indicate larger clusters have more defective $\mathrm{Au}_{4}$ units within their core structures. Table 2 summarizes our quantitative analysis of the Au-Au metallic bonds for the $\mathrm{Au}_{4}$ units in each cluster, including the ratio of observed metallic bonds to ideal metallic bonds (for a perfect $\mathrm{Au}_{4}$ tetrahedron) within the $\mathrm{Au}_{4}$ units. As the size of the clusters increases, the ratio decreases from $100 \%$ for $A u_{28}(S R)_{20}$ to $94 \%$ for

Table 2. Number of Au-Au bonds in first Au-Au scattering shells (a), number of Au-Au bonds in the ideal first Au-Au scattering shells (b), and the ratio of a to b.

\begin{tabular}{|c|c|c|c|}
\hline Au clusters & $\#$ of $A u-A u_{1}$ bonds (a) & Ideal \# of $A u-A u_{1}$ bonds (b) & $\mathrm{a} / \mathrm{b}(\%)$ \\
\hline $\mathrm{Au}_{28}(\mathrm{SR})_{20}$ & 24 & 24 & 100 \\
\hline$A u_{36}(S R)_{24}$ & 34 & 36 & 94 \\
\hline $\mathrm{Au}_{44}(\mathrm{SR})_{28}$ & 38 & 48 & 83 \\
\hline
\end{tabular}


$\mathrm{Au}_{36}(\mathrm{SR})_{24}$ and then to $83 \%$ for $\mathrm{Au}_{44}(\mathrm{SR})_{28}$ (Table 2). In other words, when the cluster size increases, the Au core exhibits more pronounced defective $\mathrm{Au}_{4}$ units.

Based on the information in Figure 6 and Table 2, we proceed to discuss the origin of the observed size-dependent NTE. For the smallest clusters, $\mathrm{Au}_{28}(\mathrm{SR})_{20}$, the core structure has a perfect $\mathrm{Au}_{4}$ based structure (i.e. no defect) and thus is the most rigid. Such a rigid core structure will exhibit the least amount of change in bond distance when temperature is varied. In contrast, the cores of larger clusters with a less perfect $\mathrm{Au}_{4}$ bonding motif, will be less rigid, and thus, more sensitive to temperature change. As a result, larger clusters will exhibit more pronounced temperature-dependent NTE. In this comparative study, $\operatorname{Au}_{44}(\mathrm{SR})_{28}$ was found to have the least rigid core structure, and thus, it exhibits the most pronounced NTE.

The size-dependent NTE trend we observed in FCC-like Au cores is an important finding which may help develop a better understanding of the growth mechanism of Au clusters. In these FCC-like Au clusters, the Au cores grow by the addition of $\mathrm{Au}_{4}$ units to the two base sets which follow a "double helix" structure. ${ }^{8}$ During the growth process, the bonding motif of $\mathrm{Au}_{4}$ units within the core is not perfectly maintained and becomes more defective when the cluster size increases. This makes the Au core less rigid, and thus, more susceptible to change upon varied conditions (i.e. temperature).

\section{Conclusions}

In conclusion, the bonding properties of $\mathrm{Au}_{44}(\mathrm{SR})_{28}$ was studied and compared with two 
Page 15 of 18

other FCC-like Au clusters, $\mathrm{Au}_{28}(\mathrm{SR})_{20}$ and $\mathrm{Au}_{36}(\mathrm{SR})_{24}$. A multi-shell EXAFS fitting analysis was first established to reliably probe the site-specific bonding properties of the $A_{44}(S R)_{28}$. Temperature-dependent EXAFS measurements indicate the existence of a negative thermal expansion behavior for the $\mathrm{Au}-\mathrm{Au}$ interactions of the $\mathrm{Au}_{44}(\mathrm{SR})_{28}$. Comparison of the bonding behavior of $\mathrm{Au}_{44}(\mathrm{SR})_{28}$ with that of $\mathrm{Au}_{28}(\mathrm{SR})_{20}$ and $\mathrm{Au}_{36}(\mathrm{SR})_{24}$ shows an interesting size-dependent trend for the negative thermal expansion behavior of the first-shell $\mathrm{Au}-\mathrm{Au}$ bonds. Specifically, the Au clusters with larger size exhibit more pronounced negative thermal expansion than the smaller ones. This observation can be understood as an effect related to the significant role of the bonding motif of $\mathrm{Au}_{4}$ units within the $\mathrm{Au}$ cores. The bonding motif of the $\mathrm{Au}_{4}$ units within the "double helix" structures of these clusters are observed to be less perfectly maintained when the size of FCC-like Au clusters increases. Our findings demonstrate the unique bonding properties of the FCC-like Au clusters, and may be further the understanding of the growth mechanism of these Au clusters.

\section{Acknowledgment}

P.Z. would like to acknowledge funding support from Dalhousie University and NSERC in the form of discovery grant. R.J. acknowledges research support from the Air Force Office of Scientific Research under AFOSR Award No. FA9550-15-1-9999 (FA9550-15-1-0154). The CLS@APS (Sector 20-BM) facilities at the APS are supported by the U.S. DOE, Basic Energy Sciences, NSERC Canada, the University of Washington, the CLS, and the APS. Use of the APS was supported by the U.S. DOE (DEAC02-06CH11357). 


\section{Reference}

(1) Jin, R. Nanoscale 2010, 2, 343-362.

(2) Jin, R.; Zeng, C.; Zhou, M.; Chen, Y. Chem. Rev. 2016, 116, 10346-10413.

(3) Zhang, P. J. Phys. Chem. C 2014, 118, 25291-25299.

(4) Chevrier, D. M.; Yang, R.; Chatt, A.; Zhang, P. Nanotechnol. Rev. 2015, 4, 193-206.

(5) Crasto, D.; Malola, S.; Brosofsky, G.; Dass, A.; Hakkinen, H. J. Am. Chem. Soc. 2014, 136, 5000-5005.

(6) Das, A.; Li, T.; Li, G.; Nobusada, K.; Zeng, C.; Rosi, N. L.; Jin, R. Nanoscale 2014, 6, $6458-6462$.

(7) Qian, H.; Eckenhoff, W. T.; Zhu, Y.; Pintauer, T.; Jin, R. J. Am. Chem. Soc. 2010, 132, $8280-8281$.

(8) Zeng, C.; Chen, Y.; lida, K.; Nobusada, K.; Kirschbaum, K.; Lambright, K. J.; Jin, R. J. Am. Chem. Soc. 2016, 138, 3950-3953.

(9) Zeng, C.; Liu, C.; Chen, Y.; Rosi, N. L.; Jin, R. J. Am. Chem. Soc. 2014, 136, 11922-11925.

(10) Zeng, C.; Li, T.; Das, A.; Rosi, N. L.; Jin, R. J. Am. Chem. Soc. 2013, 135, 10011-10013.

(11) Zeng, C.; Qian, H.; Li, T.; Li, G.; Rosi, N. L.; Yoon, B.; Barnett, R. N.; Whetten, R. L.; Landman, U.; Jin, R. Angew. Chemie - Int. Ed. 2012, 51, 13114-13118.

(12) Zhu, M.; Aikens, C. M.; Hollander, F. J.; Schatz, G. C. J. Am. Chem. Soc. 2008, 130, 5883-5885.

(13) Das, A.; Liu, C.; Byun, H. Y.; Nobusada, K.; Zhao, S.; Rosi, N.; Jin, R. Angew. Chemie - Int. Ed. 2015, 54, 3140-3144.

(14) Das, A.; Li, T.; Nobusada, K.; Zeng, C.; Rosi, N. L.; Jin, R. J. Am. Chem. Soc. 2013, 135, 
Page 17 of 18

$18264-18267$.

(15) Jadzinsky, P. D.; Calero, G.; Ackerson, C. J.; Bushnell, D. A.; Kornberg, R. D. Science. 2007, 318, 430-433.

(16) Chevrier, D. M.; Chatt, A.; Zhang, P.; Zeng, C.; Jin, R. J. Phys. Chem. Lett. 2013, 36, 3186-3191.

(17) Chevrier, D. M.; Zeng, C.; Jin, R.; Chatt, A.; Zhang, P. J. Phys. Chem. C 2015, 119, 12171223.

(18) Shivhare, A.; Chevrier, D. M.; Purves, R. W.; Scott, R. W. J. J. Phys. Chem. C 2013, 25, 20007-20016.

(19) Macdonald, M. A.; Chevrier, D. M.; Zhang, P.; Qian, H.; Jin, R. J. Phys. Chem. C 2011, $115,15282-15287$.

(20) Macdonald, M. A.; Zhang, P.; Chen, N.; Qian, H.; Jin, R. J. Phys. Chem. C 2011, 115, 6569.

(21) Zeng, C.; Chen, Y.; Kirschbaum, K.; Lambright, K. J.; Jin, R. Science. 2016, 354, 15801584.

(22) Xu, W. W.; Li, Y. D.; Gao, Y.; Zeng, X. C. Nanoscale 2016, 8, 7396-7401.

(23) Tian, Z.; Cheng, L. Nanoscale 2015, 8, 826-834.

(24) Ma, Z.; Wang, P.; Pei, Y. Nanoscale 2016, 8, 17044-17054.

(25) Ressler, T. J. Synchrotron Radiat. 1998, 5, 118-122.

(26) Ankudinov, A. L.; Ravel, B.; Rehr, J. J.; Conradson, S. D. Phys. Rev. B 1998, 58, 75657576. 
